\title{
Tage der Wahrheit
}

\section{Liebe Leserin, lieber Leser,}

was aktuelle Motoren- und Antriebstechnologien betrifft, kennen wir die Trends spätestens seit dem Wiener Motorensymposium im Mai. Die „Tage der Wahrheit“ erleben wir nun bei der IAA vom 17. bis 27. September. Denn wenn die Hersteller auf der bedeutendsten Automobilmesse der Welt ihre neuen Modelle enthüllen, wird allen klar werden, welche Antriebe und Lösungen es tatsächlich in die Serienproduktion geschafft haben. Und vor allem in welche Fahrzeugsegmente.

Ganz deutlich ist bereits im Vorfeld geworden: Der Druck, Flottenverbräuche zu senken, wirkt sich über Marken, Modelle und Segmente hinweg aus. So schlägt sich Downsizing nicht mehr nur auf einzelne Motoren oder Klassen nieder. Opel beispielsweise wird den Astra der Generation K zum Verkaufsstart mit nur drei verschiedenen Grundmotoren anbieten; neben einem 1,0- sowie einem 1,4-1-Ottomotor ist ein Dieselmotor mit 1,6 1 Hubvolumen angekündigt. Damit bildet der Hersteller zunächst alle Leistungsstufen ab. Selbst Porsche setzt beim 911 künftig, bis auf den GT3, nur noch auf Turboaufladung. Wohlgemerkt nicht als Spitzenmotorisierung, sondern als Standard. Statt 3,4 und 3,8 1 sind so 2,7 und 3,0 1 Hubvolumen möglich. Das ist fast schon ein Paradigmenwechsel in der Sportwagen-Welt.

Audi bietet mit der Premiere seines neuen A4 den 2,0-1-Vierzylinder-Ottomotor erstmalig mit einer weiterentwickelten Form des Miller-Brennverfahrens an. Toyota setzte schon beim ersten Prius auf alternative Ventilsteuerzeiten, präsentiert nunmehr die vierte Generation des Voll-Hybriden. Innovative Antriebskonzepte, die wir in der Titelstrecke beleuchten, stehen deshalb im Entwicklungsfokus von OEMs und Zulieferern. Sowohl Serienfahrzeuge als auch Konzeptstudien - wie Power-E-Drive von BMW - zeigen, dass der Weg dorthin vielseitig ist. Ebenso interessant sind die Ausführungen von Professor Küçükay zu speziellen Hybridgetrieben. Wir sind gespannt, in Frankfurt mehr zu erfahren. Wie Sie ganz sicher auch.

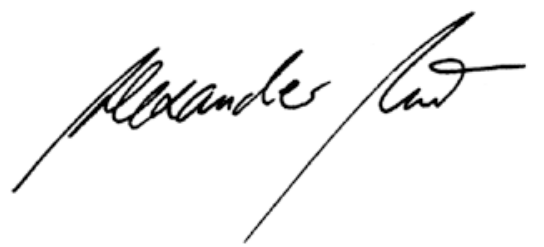

Dr. Alexander Heintzel Chefredakteur

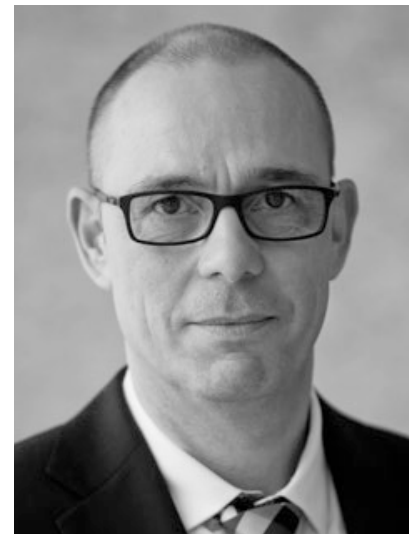

Wir

\section{entwickeln, was bewegt.}

IAV - Ihr Partner

für Automotive Engineering 